\title{
INOVAÇÕES SOCIOAMBIENTAIS EM CADEIAS DE SUPRIMENTO: UM ESTUDO DE CASO SOBRE O PAPEL DA EMPRESA FOCAL
}

\author{
André Pereira de Carvalho \\ Doutor em Administração de Empresas pela Fundação Getulio Vargas - SP \\ Pesquisador de Centro de Estudos da Fundação Getulio Vargas - SP \\ andre.carvalho@fgv.br (Brasil)
}

\section{José Carlos Barbieri}

Doutor em Administração de Empresas pela Fundação Getulio Vargas - SP

Professor Adjunto da Fundação Getulio Vargas - SP

jose.barbieri@fgv.br (Brasil)

\section{RESUMO}

Este artigo apresenta os resultados de uma pesquisa que procura responder a seguinte questão: como a empresa focal induz e implementa práticas socioambientais inovadoras em uma cadeia de suprimento orientada à sustentabilidade? Por empresa focal entende-se aquela que estabelece regras ou governa a cadeia de suprimento, mantém contato direto com o consumidor ou projeta os produtos que a cadeia oferece. Inicialmente, realiza-se uma discussão sobre gestão da cadeia de suprimento e sustentabilidade para definição do marco conceitual da pesquisa relatada e, a seguir, são examinados modelos de gestão de cadeias de suprimento sustentáveis. Tais cadeias visam simultaneamente resultados econômicos, sociais e ambientais positivos, de acordo com os objetivos do desenvolvimento sustentável, que, no âmbito empresarial, tem no modelo triple bottom line (TBL) uma de suas expressões mais importantes. Apresenta-se, então, um estudo de caso em duas cadeias de suprimento baseadas em ativos da biodiversidade envolvendo seis organizações à montante da empresa focal. Duas estratégias de indução de inovações são consideradas: uma centrada em requisitos impostos aos fornecedores e outra em desenvolvimento de novos produtos. O estudo aponta evidências de que as inovações em cadeias orientadas à sustentabilidade requerem a criação de instrumentos de indução pela empresa focal, bem como de cooperação entre os membros da cadeia, mostra a pertinência do modelo de indução adotado e suas possibilidades de replicação. $O$ estudo permite ainda que sejam feitos acréscimos ao modelo, contribuindo para a construção de teoria sobre gestão de cadeias de suprimento sustentáveis e sua relação com as inovações.

Palavras-chave: Inovação; Sustentabilidade; Cadeia de suprimento sustentável; Empresa focal; Biodiversidade. 


\section{INTRODUÇÃ̃O}

As organizações empresariais têm sido cada vez mais cobradas pela sociedade a atuar por meio de modelos de gestão alinhados às propostas do desenvolvimento sustentável, entendido como um desenvolvimento "que atende às necessidades do presente, sem comprometer a possibilidade das futuras gerações atenderem suas próprias necessidades" (Comissão Mundial sobre Meio Ambiente e Desenvolvimento [CMMAD], 1991, p. 46). Nesse contexto, entende-se que a empresa está contribuindo para o desenvolvimento sustentável quando sua atuação gera resultados positivos em termos econômicos, sociais e ambientais. Um modelo gerencial que traduz essa ideia, conhecido por triple bottom line (TBL), segundo seu criador, Elkington (2004), leva a organização a se concentrar não apenas sobre o valor econômico que adiciona, mas também sobre o valor social e ambiental que cria ou destrói. Em um cenário de crescente operação das organizações por meio de cadeias de suprimento, espera-se que se leve em conta o relacionamento das empresas com seus fornecedores e clientes com base nas ideias desse modelo de gestão. Desse modo, a responsabilidade das empresas e suas contribuições ao desenvolvimento sustentável extravasam o seu ambiente interno, o que gera a necessidade de agir com os demais membros da cadeia de suprimento. Para autores como Andersen e Skjoett-Larsen (2009) e Jenkins (2001), as empresas podem ser responsabilizadas não apenas pelo que ocorre no ambiente intraorganizacional, mas também por práticas ambientais, empregatícias e comerciais dos seus parceiros que fornecem produtos e serviços de forma direta ou indireta.

Nesse contexto, desempenha especial papel a empresa focal, aquela que estabelece regras ou governa a cadeia de suprimento, mantém contato direto com o consumidor ou projeta os produtos que a cadeia oferece (Seuring \& Müller, 2008a). Por ser a que possui o poder de influenciar a sua cadeia, a empresa focal é um elo fundamental para a realização de inovações que introduzam práticas sustentáveis entre os membros da cadeia. O poder de influenciar outros membros da cadeia resulta de vários fatores, alguns ligados à estrutura do seu setor econômico, como grau de concentração, escala, barreiras à entrada e domínio da tecnologia; e outros, à capacidade de coordenar e liderar processos de integração, por exemplo, estabelecendo incentivos apropriados à cooperação e introduzindo inovações que agreguem valor ao longo da cadeia. Considerando as questões acima, a presente pesquisa procurou contribuir para a construção de teoria em gestão socioambiental em cadeias de suprimento analisando o seguinte problema: como a empresa focal induz e implementa práticas socioambientais inovadoras em uma cadeia de suprimento orientada à sustentabilidade? Essas práticas podem referir-se aos diferentes tipos de inovação, como inovações tecnológicas de produto e processo,

Revista de Administração e Inovação, São Paulo, v. 10, n.1, p.232-256, Jan./Mar. 2013. 
inovações organizacionais ou de marketing, conforme a tipologia do Manual de Oslo (Organisation for Economic Co-operation and Development [OCDE], 2005).

\section{SUSTENTABILIDADE E GESTÃO DA CADEIA DE SUPRIMENTO}

Desde a década de 1990, surgem conceitos que incorporam preocupações ambientais à gestão da cadeia de suprimento (supply chain management, SCM), tais como: gestão ambiental da cadeia de suprimento (supply chain environmental management, SCEM) (Lippman, 2001); gestão da cadeia de suprimento ambiental (environmental supply chain management, ESCM) (Walker, Sisto, \& Mcbain, 2008); gestão da cadeia de suprimento verde (green supply chain management, GSCM) (Srivastava, 2007) e cadeias de suprimento de ciclo-fechado (closed-loop supply chain, CLSC) (Beamon, 1999). Apesar das denominações diferentes, pode-se entender que todos esses conceitos se referem à mesma preocupação, a incorporação de preocupações ambientais na cadeia de suprimento, ou seja, tratam de duas dimensões da sustentabilidade: a econômica e a ambiental. A dimensão social é incorporada à SCM inicialmente em abordagens como gestão da cadeia de suprimento responsável (responsible supply chain management, RSCM) (Bakker \& Nijhof, 2002, Park-Poaps \& Rees, 2010). Como a dimensão ambiental não é explicitada nessa concepção de cadeia, pode-se afirmar que também trata de apenas duas dimensões da sustentabilidade.

O processo de convergência da abordagem TBL à SCM ganha um significativo impulso a partir de 2008 com a publicação dos trabalhos de Carter e Rogers (2008), Pagell e Wu (2009) e Seuring e Müller (2008b), que apresentam definições e proposições de modelos conceituais de gestão da cadeia de suprimento sustentável (SSCM, do inglês: Sustainable Supply Chain Management), examinados a seguir. Com base em definições consagradas de SCM e em revisão da literatura sobre sustentabilidade no âmbito intraorganizacional, Carter e Rogers (2008, p. 368) definem SSCM como “[...] integração e realização estratégica e transparente de metas sociais, ambientais e econômicas da organização na coordenação sistêmica de processos interorganizacionais de negócios com o objetivo de melhorar o desempenho econômico de longo-prazo da empresa e de suas cadeias de suprimento". O modelo proposto para SSCM, apresentado na Figura 1, é uma adaptação da abordagem TBL, originariamente aplicada às organizações individualmente consideradas, à lógica de SSCM.

Revista de Administração e Inovação, São Paulo, v. 10, n.1, p.232-256, Jan./Mar. 2013. 


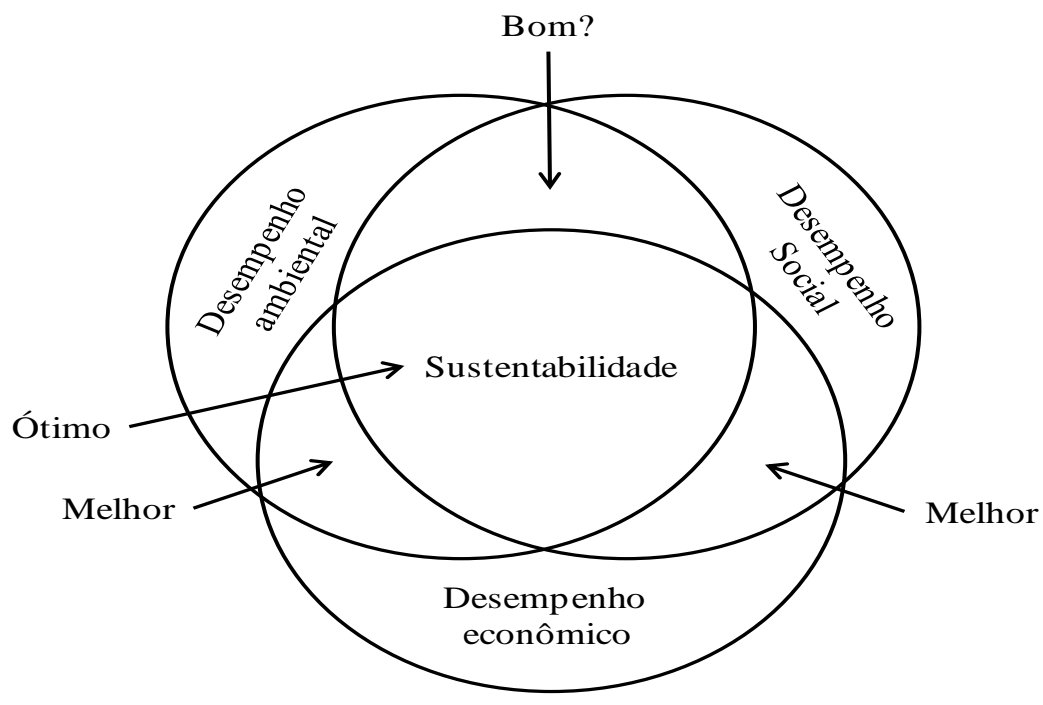

Figura 1 - SSCM: Modelo de Carter e Rogers

Fonte: Carter e Rogers (2008).

Como mostra a Figura 1, as práticas sociais e ambientais que não contribuem para o desempenho econômico da cadeia de suprimento são questionadas (bom?). As práticas que em separado apresentam sobreposições com a dimensão econômica são melhores para a sustentabilidade da cadeia do que as anteriores, porém, somente as que apresentam resultados positivos nas três dimensões da TBL são consideradas atividades sustentáveis (ótimo), alcançadas apenas quando "a organização incorporar, de forma explícita e abrangente, metas sociais, ambientais e econômicas no desenvolvimento de uma visão estratégica e de objetivos estratégicos de longo prazo" (Carter \& Rogers, 2008, p. 371).

Pagell e Wu (2009, p. 38) entendem que a SSCM diz respeito “[...] às ações de gestão específicas que são tomadas para tornar a cadeia de suprimento mais sustentável com o objetivo final de criar uma cadeia verdadeiramente sustentável.” e sugerem que “[...] as práticas que conduzem à cadeia de suprimento sustentável são, em partes iguais, melhores práticas em gestão da cadeia de suprimento tradicional e novos comportamentos" (p. 51), conforme apresentado na Figura 2. A sustentabilidade se tornará integrada à organização quando esta possuir capacidade de inovação e uma gestão orientada à sustentabilidade.

Revista de Administração e Inovação, São Paulo, v. 10, n.1, p.232-256, Jan./Mar. 2013. 


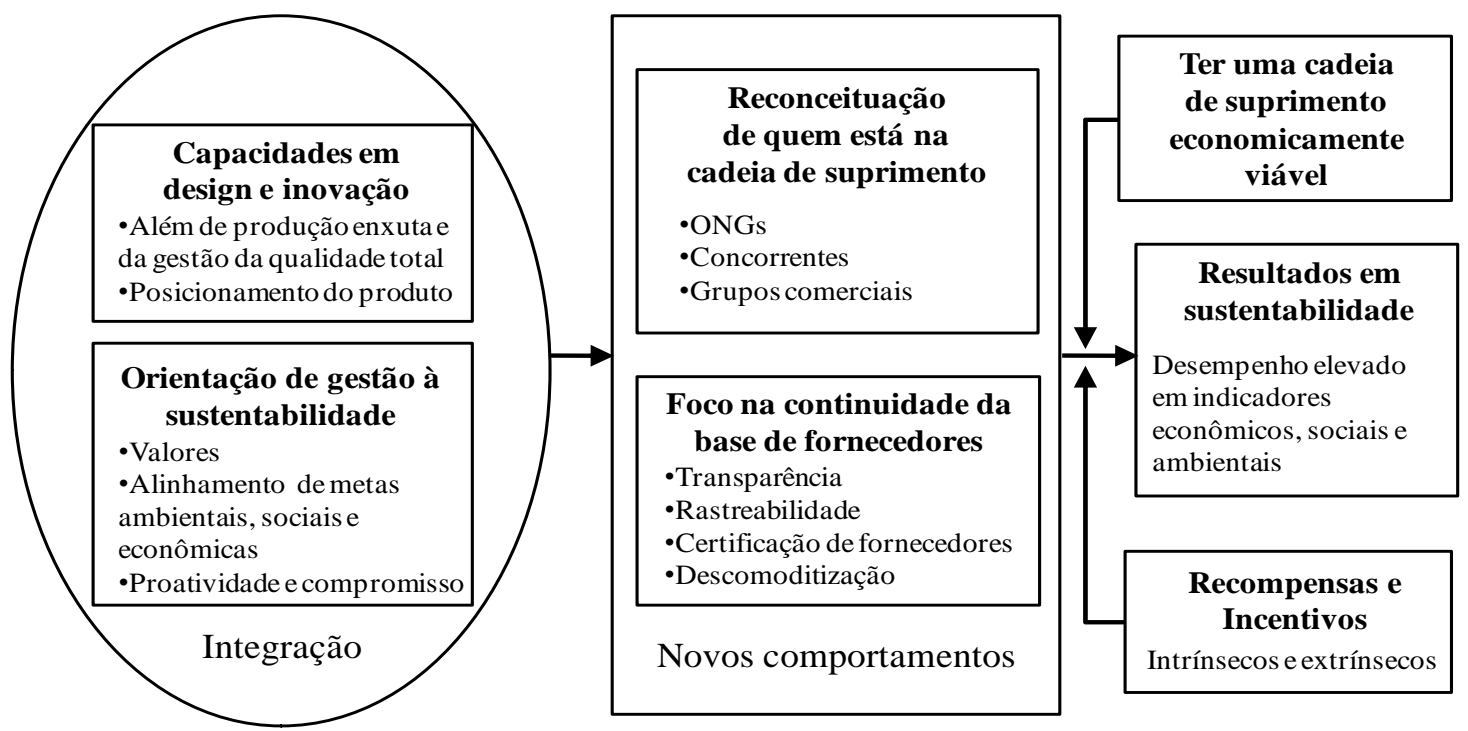

Figura 2 - SSCM: Modelo de Pagell e Wu

Fonte: Pagell e Wu (2009).

Uma característica verificada nas empresas focais orientadas à sustentabilidade é o alinhamento interno do negócio por meio de metas sociais e ambientais de forma que o desempenho social e ambiental torna-se um dos seus fatores críticos. Uma vez inseridas no negócio, essa metas são repassadas também à cadeia de suprimento. Entre os novos comportamentos identificados em SSCM, Pagell e Wu (2009) apontam dois grupos: um novo conceito de cadeia de suprimento que incorpora outros membros além de fornecedores diretos e clientes, tais como organizações não governamentais (ONGs) e comunidades; e um foco explícito na continuidade da base de fornecedores, que busca garantir à empresa focal uma base estável e capaz de atender às demandas da cadeia de suprimento por meio das seguintes práticas: descomoditização, transparência, rastreabilidade e certificação, além de iniciativas de desenvolvimento de fornecedores.

Seuring e Müller (2008b, p. 1700), com base em ampla revisão da literatura sobre temas socioambientais no âmbito interorganizacional, constatam, inicialmente, que o desenvolvimento sustentável resume-se à realização de melhorias ambientais. Incorporando a abordagem TBL à SCM, esses autores definem SSCM como: “[...] a gestão dos fluxos de materiais, informações e capital, assim como a cooperação entre empresas da cadeia de suprimento para alcançar as três dimensões do desenvolvimento sustentável: econômica, ambiental e social, considerando-se as necessidades dos consumidores e das partes interessadas". A inserção de sustentabilidade na cadeia de suprimento se dá por pressões e incentivos que resultam da ação de diferentes grupos externos à cadeia posicionados no lado da demanda (Figura 3): clientes (grupo de maior importância e alvo da SCM), governos (todos os 
modos de atuação governamental, desde o âmbito local ao nacional e multinacional) e stakeholders. Quando a empresa focal é objeto de pressões tais quais demandas legais, de clientes ou de demais stakeholders, ela frequentemente as repassa à cadeia de suprimento. Se as pressões dizem respeito ao ciclo de vida do produto e/ou aos membros da cadeia com os quais não tenha relacionamento direto, a empresa focal terá necessariamente que considerar níveis mais distantes de sua cadeia para oferecer respostas ou soluções, algo que não se justificaria numa tomada de decisão baseada puramente na dimensão econômica.

Pressões e incentivos para a adoção de práticas de sustentabilidade afetam a colaboração com fornecedores, desde a obtenção de informações sobre aspectos sociais e ambientais da produção dos fornecedores posicionados em elos iniciais da cadeia (ex: produção de matérias-primas) até a busca por melhoria de desempenho dos principais fornecedores da cadeia.

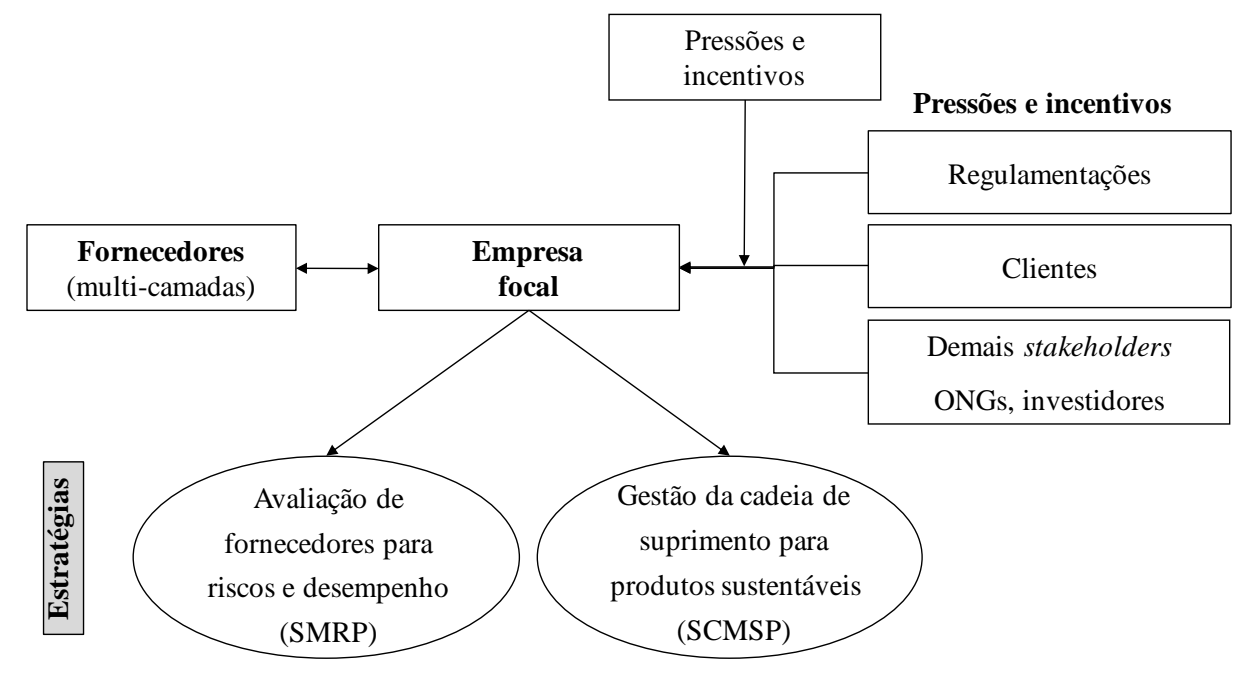

Figura 3 - SSCM: Modelo de Seuring e Müller

Fonte: Seuring e Müller (2008b).

As empresas focais podem lidar com tais pressões e incentivos por meio de duas estratégias. A primeira, mais comum, caracteriza-se por ações e iniciativas focadas em fornecedores, com o objetivo de obter garantias de que práticas socioambientais mais adequadas estão sendo adotadas ao longo da cadeia que é objeto de pressões. Tal estratégia é denominada: avaliação de fornecedores para riscos e desempenho (supplier management risk and perfomance, SMRP). A segunda estratégia diz respeito a preocupações com os atributos de sustentabilidade do produto; essa estratégia é denominada gestão da cadeia de suprimento para produtos sustentáveis (supply chain management for sustainable products, SCMSP) e sua implementação acaba por se refletir positivamente no processo produtivo. Essas duas estratégias são examinadas a seguir.

Revista de Administração e Inovação, São Paulo, v. 10, n.1, p.232-256, Jan./Mar. 2013. 
Os modelos de Pagell e Wu (2009) e de Seuring e Müller (2008b) são adequados à análise da indução e implementação de inovações socioambientais em cadeias de suprimento por uma empresa focal e pode-se considerá-los como modelos complementares. Como o relacionamento com os fornecedores mostra-se mais explícito no modelo de Seuring e Müller (2008b), ele foi utilizado como modelo teórico deste trabalho de pesquisa. Em razão dessa escolha, são examinadas a seguir as duas estratégias de indução e implementação de inovações desse modelo.

\subsection{MODELO DE SEURING E MÜLLER - ESTRATÉGIA SMRP}

A estratégia SMRP tem seu foco principal na adequação do processo produtivo a demandas socioambientais mais rigorosas, como mostra a Figura 4.

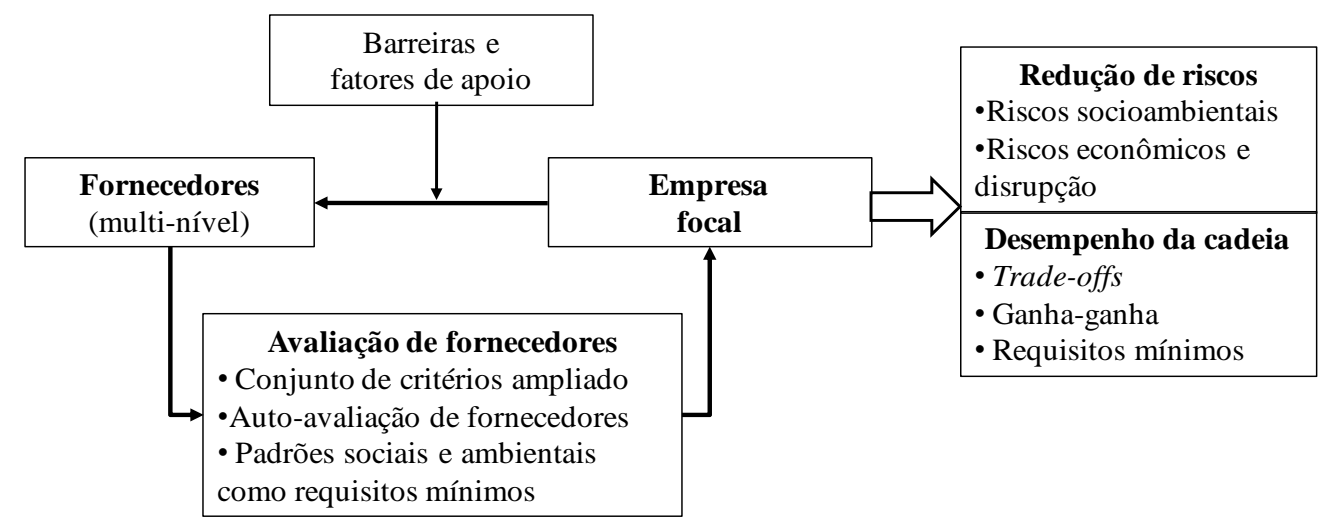

Figura 4 - SSCM: Modelo de Seuring e Müller - detalhamento da estratégia SMRP Fonte: Seuring e Müller (2008b).

Para evitar os riscos de reputação ou para recuperar a imagem da organização pós-danos, a empresa focal inicia e consolida um processo de incorporação de critérios sociais e ambientais para a avaliação de fornecedores. Padrões socioambientais, tais quais sistemas de gestão ambiental e social, desempenham um papel central nessa abordagem, que também pode utilizar-se de autoavaliações de fornecedores e de compromissos desses em relação a impactos socioambientais de suas operações. $\mathrm{O}$ estabelecimento de requisitos mínimos aos membros da cadeia, pela empresa focal, usualmente extrapola o objetivo de reduzir o risco de reputação associados aos problemas socioambientais, gerando resultados positivos também em relação à gestão do risco de interrupção de processos operacionais, comumente tratado na literatura de SCM convencional.

A intensificação da atividade de avaliação e monitoramento de fornecedores ainda resulta, em muitos casos, na melhoria do desempenho da cadeia como um todo, seja pela exploração de 
oportunidades ganha-ganha, frequentemente apresentadas na literatura de gestão e sustentabilidade majoritariamente restritas às dimensões econômica e ambiental. A melhoria pode ser verificada também em aspectos como qualidade, agilidade, flexibilidade e custo. Os fornecedores, por sua vez, tendem a perceber os critérios socioambientais impostos pela empresa focal como pré-requisitos à sua manutenção na cadeia de suprimento. Isso os estimula a agirem de acordo com requisitos mínimos definidos, mesmo em alguns casos em que a empresa focal que os estabelece não é o seu principal cliente (Seuring \& Müller, 2008b).

\subsection{MODELO DE SEURING E MÜLLER - ESTRATÉGIA SCMSP}

A estratégia SCMSP tem como objetivo a satisfação do cliente e o ganho de vantagem competitiva da empresa focal e de sua cadeia no mercado (Figura 5). A SCMSP tem como alvo os produtos sustentáveis, entendidos como "produtos que têm ou buscam qualidade ambiental e social melhoradas" (Seuring \& Müller, 2008b, p. 1705).

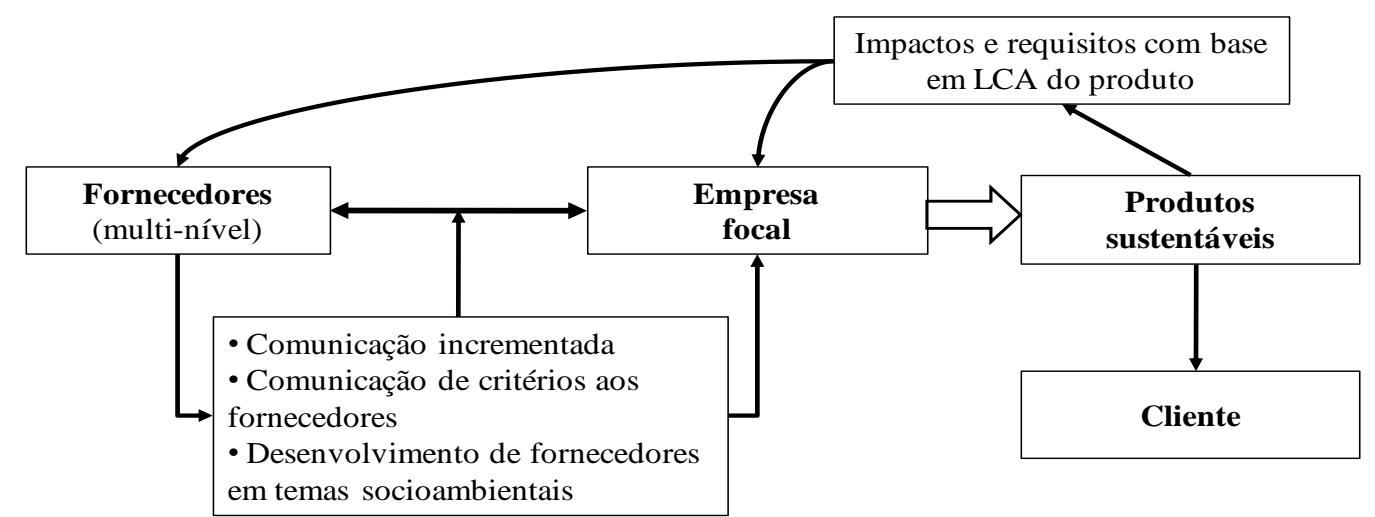

Figura 5 - SSCM: Modelo de Seuring e Müller - detalhamento da estratégia SCMSP Fonte: Seuring e Müller (2008b).

A especificação de produtos sustentáveis tem na avaliação de ciclo de vida (life-cycle analysis, LCA) uma ferramenta essencial para garantir que a empresa focal tome decisões mais acertadas, a partir do exame de um espectro mais amplo de informações acerca dos impactos socioambientais dos produtos e do modelo de negócio por meio do qual pretende ofertá-los ao mercado. Ressalte-se que tais decisões afetam toda a cadeia de suprimento, à montante e à jusante, bem como a vida útil e o pósconsumo das mercadorias em análise.

A SSCM apresenta três aspectos que a distinguem da SCM: (i) requer o exame de um número maior de impactos em uma cadeia de suprimento estendida; (ii) considera um grupo mais numeroso de 
objetivos de desempenho em razão da inserção das dimensões ambiental e social da sustentabilidade; e (iii) apresenta maior necessidade de integração e cooperação entre membros da cadeia de suprimento (Seuring \& Müller, 2008b, p. 1705-1706).

Deve-se ressaltar que as estratégias SMRP e SCMSP não são opostas, mas ambivalentes; além de perceptíveis de forma simultânea numa organização, podem apoiar-se mutuamente, fortalecendo a SSCM da empresa focal. Embora a segunda estratégia, em razão da maior complexidade, possa ser vista como resultado de um processo de amadurecimento da empresa focal, o caminho inverso também pode ser verificado.

\section{METODOLOGIA}

Para responder a pergunta de pesquisa apresentada na introdução foi utilizada uma pesquisa com base no método qualitativo. Para Creswell (2010), entre as estratégias apropriadas às pesquisas qualitativas estão os estudos de casos, nos quais o pesquisador explora profundamente programas, eventos, atividades e indivíduos. Para Yin (2010), na definição do método de pesquisa são necessárias três condições: o tipo da questão de pesquisa; a extensão do controle do pesquisador sobre eventos comportamentais efetivos, e o grau de enfoque nos acontecimentos contemporâneos em oposição aos históricos. O estudo de caso é apropriado para pesquisas que procuram responder questões do tipo como e por que; que não exigem controle do pesquisador sobre os eventos comportamentais; e para explorar acontecimentos contemporâneos (Yin, 2010). Essas três condições estão presentes nessa pesquisa, que, repetindo, procura responder a questão: como a empresa focal induz e implementa práticas socioambientais inovadoras em uma cadeia de suprimento orientada à sustentabilidade? O pesquisador não tem controle sobre os eventos pesquisados e o tema é contemporâneo. Uma vantagem da aplicação dessa metodologia em SCM é que ela permite a observação direta do campo, o que pode ser apropriado para abordar diversos níveis de uma cadeia de suprimento (Seuring, Sarkis, Muller, \& Rao, 2008). Essa vantagem é pouco explorada na opinião de Seuring (2005), pois são poucos os exemplos de pesquisas com dois ou mais níveis ou camadas das cadeias analisadas, em geral apenas um nível é abordado. Como dizem Kemp e Foxon (2007), o processo de inovação pode ser mais bem visualizado como um processo de busca e aprendizado envolvendo a gestão de múltiplos elos.

A pesquisa realizada analisou três níveis à montante de duas cadeias da Natura Cosméticos S.A., cuja escolha observou os seguintes critérios: a empresa selecionada deveria ser reconhecida por suas práticas de sustentabilidade em rankings ou premiações prestigiadas pela sociedade e pelo ambiente

Revista de Administração e Inovação, São Paulo, v. 10, n.1, p.232-256, Jan./Mar. 2013. 
empresarial de modo geral. Escolheu-se o Índice de Sustentabilidade Empresarial (ISE) da BM\&FBovespa, que desde 2005 avalia as empresas listadas nessa Bolsa de Valores segundo critérios sociais, ambientais, de governança corporativa e impactos dos produtos ou serviços comercializados. Para contribuir com o desenvolvimento da teoria em gestão sustentável de cadeias de suprimento e, especificamente, a atuação da empresa focal para torná-la mais sustentável, a unidade de análise desse estudo é a indução de práticas de sustentabilidade pela empresa focal em sua cadeia. Assume-se que essas práticas equivalem às ações alinhadas às estratégias SMRP e SCMSP como proposto por Seuring e Müller (2008b) e comentadas acima. Duas cadeias foram escolhidas para estudos - cacau em amêndoas e priprioca - conforme apresentado a seguir.

\section{APRESENTAÇÃO DO ESTUDO DE CASO}

A pesquisa foi realizada, entre julho de 2011 e fevereiro de 2012, por meio de entrevistas semiestruturadas, análise de documentos e observações locais ao longo da cadeia, atendendo ao requisito da utilização de várias fontes de evidências, conforme recomenda Yin (2010). As entrevistas foram feitas com representantes dos membros das cadeias de suprimento estudadas, o que requereu visitas aos fornecedores, inclusive os do terceiro e último nível. Os principais documentos analisados foram os relatórios de sustentabilidade, balanços sociais e patrimoniais, documentos de planejamento, relatórios de auditoria, programas de trabalho diversos, entre outros. Ao todo, 28 profissionais foram entrevistados entre setembro de 2010 e julho de 2011, sendo 20 deles presencialmente e nove por telefone. Na Natura, foram realizadas entrevistas com 15 profissionais ligados às áreas de Operações e Logística, Gerência de Relacionamento com Comunidades (GRC), Sustentabilidade e Qualidade das Relações. Buscou-se examinar os atributos internos de sustentabilidade da empresa, além de suas iniciativas para indução e implementação de práticas socioambientais. Nos demais membros das duas cadeias estudadas, foram priorizados os contatos com os responsáveis pelo relacionamento com o cliente Natura e com o fornecedor em análise.

\subsection{A EMPRESA FOCAL: NATURA}

A Natura é uma empresa brasileira fundada em 1969 que atua no setor de produtos de higiene pessoal, perfumaria e cosméticos, oferecendo 10 categorias de produtos, dentre os quais: sabonetes, xampus, desodorantes, perfumes, protetores solares, etc. A empresa tem operações próprias na Argentina, Chile, Colômbia, México, Peru e França. Sua atuação na América Latina é completada por

Revista de Administração e Inovação, São Paulo, v. 10, n.1, p.232-256, Jan./Mar. 2013. 
meio de distribuidores locais em El Salvador, Bolívia, Guatemala e Honduras. Exceto na França, a empresa adota o modelo de venda direta, por meio do qual se relaciona com mais de 1,2 milhão de representantes comerciais, denominados Consultoras(es) Natura (CN) e que se encontram majoritariamente no Brasil (98\%). Em 2010, a empresa apresentava quatro fábricas (três unidades em Cajamar, no Estado de São Paulo, e uma em Benevides, no Estado do Pará), uma central de armazenamento em Jundiaí (SP), oito centros de distribuição no Brasil e quatro na América Latina.

A cadeia de suprimentos da Natura apresenta mais de 4,9 mil fornecedores, dos quais cerca de 240 são os fornecedores produtivos, conforme denominação da empresa, pois proveem componentes dos seus produtos finais, tais quais ativos da biodiversidade, matérias-primas e materiais de embalagem. Destes, há um grupo de 31 fornecedores (associações, cooperativas e empresas rurais) que produzem os insumos da biodiversidade por meio de plantio ou extrativismo. A Natura exige que todos os fornecedores produtivos se autoavaliem em relação aos aspectos de qualidade, meio ambiente e responsabilidade social, incluindo direitos humanos em riscos como trabalho infantil, trabalho forçado ou em condições análogas ao escravo, discriminação por raça, crença ou gênero.

O relacionamento da Natura com os fornecedores se dá por meio do programa Qualidade, Logística, Inovação, Competitividade, Atendimento e Relacionamento (QLICAR), que se apresenta como um canal para fomentar a cooperação em temas socioambientais ao longo da cadeia de suprimento. Desde 2008, todos os membros do QLICAR são auditados. Em 2010, esse programa contemplava 75 organizações responsáveis por mais de 90\% das compras da empresa. Observou-se que ao longo dos anos, o QLICAR evoluiu de um programa de avaliação para um modelo de relacionamento mais amplo da Natura com seus fornecedores, envolvendo mais cooperação entre as organizações no desenvolvimento conjunto de soluções em processos e produtos, com o objetivo principal de alavancar o desempenho da cadeia como um todo. Nesse contexto, aspectos socioambientais relacionados à cadeia de suprimentos ganham relevância. Quanto à indução e implementação de práticas socioambientais, o QLICAR, que inicialmente estava voltado apenas à imposição de requisitos conforme a abordagem SMRP, comentada na seção 2.1, nos últimos anos também incorporou componentes característicos da SCMSP, comentada na seção 2.2.

Exemplo de cooperação em temas socioambientais na cadeia de suprimento se dá no âmbito do projeto Carbono Neutro: a área de Operações e Logística (OL) criou um grupo de trabalho para analisar a matriz energética dos fornecedores e desenvolver estratégias de redução de suas emissões de gases de efeito estufa (GEE). A iniciativa tem o objetivo de alinhar a cadeia de suprimento às metas de emissões de GEE da empresa e espera-se que um segundo passo seja dado pelos fornecedores, ao assumirem metas semelhantes e multiplicarem essa ação junto aos seus próprios fornecedores.

Revista de Administração e Inovação, São Paulo, v. 10, n.1, p.232-256, Jan./Mar. 2013. 
O relacionamento com organizações de menor porte, como associações e cooperativas, se dá por meio do programa BIOQLICAR, que envolve avaliação, monitoramento e desenvolvimento de fornecedores. Mais do que uma adaptação do QLICAR para o contexto de pequenas organizações, o BIOQLICAR tem por objetivos: (i) implementar a Política Natura de Uso Sustentável da Biodiversidade e do Patrimônio Cultural; (ii) criar um canal transparente e objetivo de diálogo com os fornecedores rurais e (iii) orientar os investimentos da Natura junto a estes grupos. Os temas prioritários eleitos em relação aos indicadores mensurados no componente BIO do programa de relacionamento são: fortalecimento de escola familiar agrícola, valorização cultural, assistência técnica, apoio à criação de fontes de renda alternativas, segurança alimentar, articulação intersetorial, formação de lideranças e realização de estudos sobre o envolvimento de jovens em cadeias produtivas.

Do ponto de vista de indução e implementação de inovações socioambientais, esse programa apresenta-se como uma ação voltada à avaliação e monitoramento de fornecedores, o que explicita atributos de uma abordagem SMRP, mas que também estabelece requisitos socioambientais baseados em avaliação do ciclo de vida e em demanda intensa de cooperação junto aos fornecedores diretos ou indiretos, o que o torna afinado com a abordagem SCMSP.

Outro componente da estratégia da Natura é o Programa de Certificação de Ativos (PCA), que tem início em 2000, desenvolvido inicialmente com o apoio da Imaflora, ONG responsável pela certificação dos ativos de acordo com dois padrões: Forest Stewardship Council (FSC), de manejo florestal, e Sustainable Agriculture Network (SAN), voltado às atividades agrícolas, dois dos mais respeitados selos socioambientais. O PCA é orientado de acordo com selos socioambientais baseados em programas voluntários de terceira parte, fundamentados em critérios múltiplos que fazem referências aos padrões socioambientais de obrigatória aplicação no produto. Devem ainda ser baseados em avaliação do ciclo de vida do produto. Além disso, o PCA inclui certificações orgânicas dos selos do Instituto BioDinâmico (IBD), Ecocert, Organización Internacional Agropecuaria (OIA) e Institute for Marketecology (IMO). A certificação orgânica, por sua vez, atesta a qualidade da matériaprima vegetal e, ao fazê-lo, busca criar uma relação de confiança com o consumidor final. Além disso, as práticas orgânicas favorecem a conservação da biodiversidade, da água e do solo e envolvem ainda aspectos sociais relacionados à sustentabilidade da produção agrícola. Como decorrência de uma gestão da inovação marcada pela avaliação do ciclo de vida, a empresa tem orientado algumas de suas ações ao modelo de inovação aberta, que se tornou conhecido com a obra de Chesbrough (2003), o que a leva a atuar de forma mais intensa em interação com outras empresas da sua cadeia de suprimento.

Revista de Administração e Inovação, São Paulo, v. 10, n.1, p.232-256, Jan./Mar. 2013. 


\subsection{CADEIA DE SUPRIMENTO DE CACAU}

O cacau é uma commodity agrícola amplamente utilizada nas indústrias de alimentos e cosméticos, cujo valor de referência é dado pela Bolsa de Nova York. A capacidade de processamento de cacau em amêndoas das empresas instaladas no Brasil é de cerca de cerca de 230 mil toneladas, o que força as moageiras a importarem matéria-prima da Ásia e África, pois a produção brasileira encontra-se próxima a 175 mil toneladas. Considerando apenas o cacau orgânico, há no Brasil apenas sete produtores certificados localizados na Bahia e no Pará.

A cadeia de suprimento do cacau, conforme observada na pesquisa, é representada na Figura 6. É composta por três organizações, além da empresa focal: a Cooperativa dos Produtores Orgânicos do Sul da Bahia (CABRUCA), que produz o cacau orgânico em amêndoas, a Indústria Brasileira de Cacau Ltda. (IBC), que o transforma em manteiga de cacau bruta, e a Croda do Brasil Ltda. (Croda), que produz a manteiga de cacau refinada, insumo da Linha Ekos da Natura.

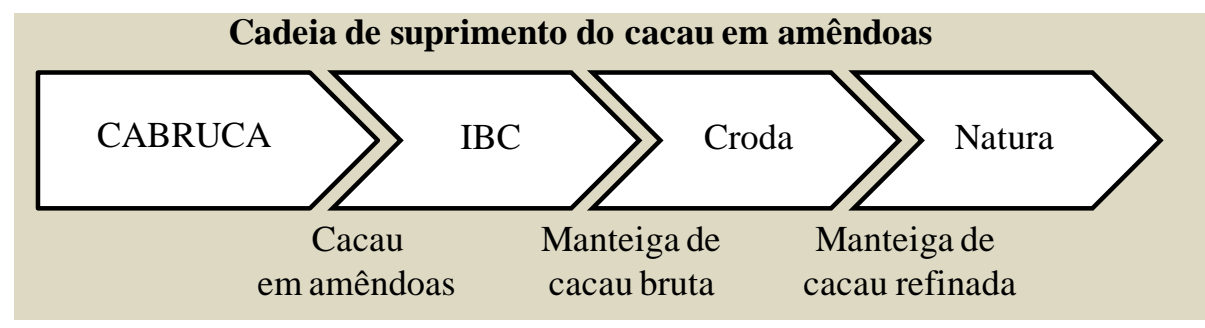

Figura 6 - Cadeia de suprimento do cacau em amêndoas Fonte: Elaborado pelos autores.

A CABRUCA foi criada em Ilhéus (BA) no ano de 2000, contando com 20 produtores rurais. Os cooperados cultivam cacau pelo método denominado cabruca, daí a denominação da Cooperativa, no qual os cacaueiros convivem entremeados com a vegetação nativa remanescente da Mata Atlântica. A Indústria Brasileira de Cacau (IBC), empresa familiar fundada em 2005, atua como processadora do cacau em amêndoas para atender empresas dos setores de alimentos e bebidas. Em 2006, a IBC obteve certificação orgânica do Instituto IBD em conformidade com os padrões do mercado brasileiro, dos EUA e da Comunidade Européia. A matéria-prima de origem convencional é comprada na região de Ilhéus (BA) ou importada da Ásia. Quanto ao insumo certificado, o principal fornecedor é a CABRUCA. A Croda é a filial brasileira da Croda Internacional, uma multinacional de origem inglesa, que produz especialidades químicas e atua no mercado business to business (B2B), sendo um dos principais fornecedores globais nos setores de cuidados pessoais, farmacêutico e industrial. Em 2000, a Croda criou a divisão industrial Crodamazon para desenvolver e fabricar óleos de espécies vegetais da Revista de Administração e Inovação, São Paulo, v. 10, n.1, p.232-256, Jan./Mar. 2013. 
região amazônica de forma sustentável, mais tarde transformada numa linha de produtos composta pelos ativos da biodiversidade como: andiroba, buriti, cacau, castanha do Brasil, cupuaçu, dentre outros. A Croda apresenta produtos com certificações do IBD e do FSC.

Os principais aspectos de indução de práticas socioambientais pela Natura identificados na cadeia de suprimento de cacau estão resumidos na Figura 7. Como se vê, ambas as estratégias de Seuring e Müller (2008b) estão presentes. Os programas QLICAR e BIOCLICAR são componentes centrais da SMRP, e a cooperação para desenvolvimento de produtos, da SCMSP, por exemplo, o desenvolvimento da manteiga de cacau refinada.

\begin{tabular}{|c|c|}
\hline SMRP & SCMSP \\
\hline $\begin{array}{l}\text { - Croda pertence ao QLICAR e é classificada } \\
\text { como fornecedor "estratégico". } \\
\text { - Croda reporta, em base trimestral, informações } \\
\text { sobre o consumo de energia e água, geração de } \\
\text { resíduos, emissões de GEE, investimentos em } \\
\text { educação formal e treinamentos para funcionários } \\
\text { e seus familiares, bem como para comunidades } \\
\text { no entorno. } \\
\text { - CABRUCA reporta quadrimestralmente } \\
\text { informações, com apoio e monitoramento de } \\
\text { GRC da Natura no âmbito do programa } \\
\text { BIOQLICAR. } \\
\text { - IBC é o membro menos integrado da cadeia. Não } \\
\text { participa do QLICAR. }\end{array}$ & $\begin{array}{l}\text { - CABRUCA já era um produtor de cacau em } \\
\text { amêndoas com certificação orgânica; não houve } \\
\text { desenvolvimento de produto. } \\
\text { - CABRUCA recebe anualmente repartição de } \\
\text { benefícios por conta de acesso ao patrimônio } \\
\text { genético: elemento de fidelização da atuação da } \\
\text { cooperativa na cadeia de suprimeto. } \\
\text { - Modelo de cadeia aberta implantado, conferindo } \\
\text { transparência e garantindo margens satisfatórias } \\
\text { para todos os membros. } \\
\text { - Cooperação Croda/Natura no desenvolvimento da } \\
\text { manteiga de cacau refinada, dentro da estratégia } \\
\text { de vegetalização da empresa. } \\
\text { - IBC foi selecionado como fornecedor também } \\
\text { por conta da exigência de selo orgânico. }\end{array}$ \\
\hline
\end{tabular}

Figura 7 - Indução e implementação de práticas socioambientais na cadeia do cacau Fonte: Elaborado pelos autores.

A cadeia de suprimento do cacau é um modelo de cadeia aberta, segundo seus membros, que se caracteriza pelos seguintes passos: (1) a área de suprimento da Natura define o volume demandado de manteiga de cacau refinada e passa essa informação à Croda; (2) a área comercial da Croda consulta sua área técnica para definir o volume de manteiga de cacau bruta a ser demandado, por meio de sua área de suprimentos, à IBC; (3) a área comercial da IBC repassa a informação sobre a quantidade de cacau em amêndoas a ser comprado junto à CABRUCA; (4) a Natura realiza a negociação de preço junto à CABRUCA; (5) o IBC realiza a contratação da produção de cacau em amêndoas junto à CABRUCA, adiciona sua margem e informa à Croda, para efetivação do contrato de compra do volume demandado de manteiga de cacau bruta; (6) Croda adiciona sua margem e informa à Natura, para efetivação do contrato de compra do volume demandado de manteiga de cacau refinada. A implementação desse modelo de cadeia aberta configura-se como uma inovação organizacional, mais propriamente inovação interorganizacional.

Revista de Administração e Inovação, São Paulo, v. 10, n.1, p.232-256, Jan./Mar. 2013. 
As inovações organizacionais referem-se à implementação de novos métodos organizacionais, tais como mudanças em práticas de negócios, na organização local de trabalho ou nas relações externas da empresa (OECD, 2005). Kemp e Pearson (2007, p. 10) definem a inovação organizacional como “a introdução de métodos e sistemas de gestão para lidar com as questões ambientais em produtos e processos". No caso estudado, esse tipo de inovação refere-se à introdução de métodos e sistemas de gestão da cadeia de suprimento para lidar com as questões econômicas, sociais e ambientais em produtos e processos, que são as três dimensões da sustentabilidade das organizações.

\subsection{CADEIA DE SUPRIMENTO DE PRIPRIOCA}

A priprioca é uma planta de ocorrência natural na Amazônia. No Pará, há três espécies conhecidas e empregadas em usos distintos, com especial destaque para a espécie Cyperus articulatus L. que é cultivada em regiões ribeirinhas e utilizada na perfumaria artesanal regional e em banhos de ervas aromáticas. O potencial de aplicação em perfumaria e cosméticos do óleo extraído da raiz dessa espécie foi constatado em 1980 por perfumistas suíços que tiveram acesso ao produto na coleção de óleos do Instituto Nacional de Pesquisas da Amazônia (INPA) e verificaram suas excelentes qualidades olfativas e fixativas (Maia \& Zoghbi, 1998). O óleo da priprioca é encontrado em quantidade muito pequena por planta: para produzir $1 \mathrm{~kg}$ de óleo essencial são necessários $500 \mathrm{~kg}$ de priprioca. Sua introdução na indústria nacional de perfumaria se deu mais de 20 anos depois da identificação do seu potencial, quando houve demonstração de interesse da Natura junto à Givaudan em relação ao desenvolvimento de uma fragrância com base em priprioca para composição do portfólio de perfumes do Brasil da linha Ekos (Zoghbi, Guilhon, Andrade, \& Vilhena, 2008).

Os usos e conhecimentos tradicionais associados à priprioca foram apresentados à Natura por meio da Associação dos Moradores de Boa Vista do Acará (AMBVA) e da Associação das Erveiras e dos Erveiros de Ver-o-Peso, localizadas, respectivamente, nos municípios de Acará e Belém, no Pará. Para atender a demanda por matéria-prima, a Natura estimulou que o cultivo da espécie Cyperus articulatus L., inicialmente restrito ao município de Acará, foi estendido ao município paraense de Santo Antônio do Tauá e à ilha de Cotijuba, em Belém. Além da AMBVA, foram desenvolvidos dois fornecedores: Associação de Produtores Rurais de Campo Limpo (APROCAM) e Movimento das Mulheres das Ilhas de Belém (MMIB). Das três comunidades fornecedoras, a APROCAM contribui com o maior volume de produção, daí porque foi selecionada para a análise desta cadeia de suprimento.

Revista de Administração e Inovação, São Paulo, v. 10, n.1, p.232-256, Jan./Mar. 2013. 
A Figura 8 representa de forma esquematizada a cadeia da priprioca, composta por três organizações, além da empresa focal: APROCAM, que produz e fornece a raiz de priprioca, a Beraca Sabará Químicos e Ingredientes S.A. (Beraca), que transforma o insumo em óleo essencial de priprioca, e a Givaudan do Brasil Ltda. (Givaudan), que produz a fragrância de priprioca a ser entregue à Natura para uso na Linha Ekos.

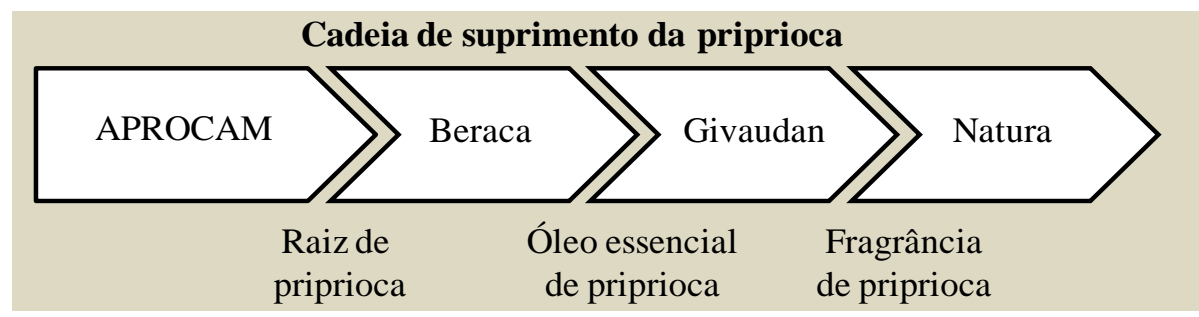

Figura 8 - Cadeia de suprimento da priprioca

Fonte: Elaborado pelos autores.

A Beraca, fundada em 1956 em São Paulo, é uma das mais importantes fornecedoras de ingredientes naturais e orgânicos para as indústrias de cosméticos, fragrâncias e farmacêutica. Ela utiliza matérias-primas provenientes da biodiversidade brasileira, em especial, da Amazônia. Metade da produção de ingredientes da biodiversidade da Beraca é exportada para mais de 45 países. Em 2006, a Beraca obteve a certificação orgânica da Ecocert para seus produtos com base na biodiversidade amazônica. Já no início da sua operação na Região Amazônica, e em decorrência do estreito contato com a Natura para o lançamento da linha Ekos, a Beraca concentrou esforços no desenvolvimento de relações sólidas com as comunidades que iriam fornecer as matérias-primas.

A Givaudan S.A. é uma empresa multinacional do setor químico com atuação no segmento de essências para aromas e fragrâncias para o mercado B2B com forte presença global em 88 países e 38 centros de produção. De origem franco-suíça, com sede em Genebra, é fornecedora de ingredientes para os setores de alimentos, bebidas, saúde, higiene e cosméticos, dentre outros. A Givaudan do Brasil Ltda. (Givaudan) atende o mercado internacional com essências derivadas de cítricos e fragrâncias extraídas da biodiversidade brasileira. Em 2010 comercializou cerca de 2 mil aromas e 6 mil fragrâncias distintas. Para o desenvolvimento de fragrâncias e criação de aromas, o relacionamento de longo prazo com seus clientes é um componente essencial para o êxito do seu modelo de negócio.

As inovações socioambientais induzidas pela Natura na cadeia da priprioca beneficiam-se inicialmente de um nível de cooperação intenso inerente às relações entre empresas de cosméticos, casas de fragrância e produtores de óleos fixos e essenciais, que envolve aspectos de qualidade e exclusividade. A Beraca havia iniciado sua operação na Amazônia, tinha experiência com a extração Revista de Administração e Inovação, São Paulo, v. 10, n.1, p.232-256, Jan./Mar. 2013. 
de óleos de origem vegetal e dava os primeiros passos no desenvolvimento do seu modelo de relacionamento com comunidades produtoras de insumos. Esses atributos fizeram com que representantes da Givaudan consultassem a Beraca sobre o interesse da organização em investir em pesquisa e desenvolvimento $(\mathrm{P} \& \mathrm{D})$ do óleo essencial de priprioca. A resposta foi afirmativa, mas como não tinha experiência com a priprioca, buscou o apoio de pesquisadores da região. Por intermédio de professores da Universidade Federal do Pará tiveram acesso à planta e foram apresentados a grupos de pequenos produtores que a cultivavam. Deu-se início então ao processo de P\&D, inicialmente com a Beraca para extrair o óleo essencial da planta, e depois com a Givaudan, para criar a fragrância com base nesse óleo.

Obtido êxito na criação da fragrância, o passo seguinte foi garantir o suprimento de priprioca de um modo economicamente viável, socialmente justo e ambientalmente correto, conforme a proposta do TBL, o que envolveu o desenvolvimento de fornecedores nas comunidades produtoras reunidas na APROCAM, MMIB e AMBVA. Em 2004, por estímulo da Natura, deu-se início a um debate sobre obtenção de certificação orgânica para a produção da APROCAM. Em 2005, representantes do IBD visitaram a comunidade para apresentar os benefícios e requisitos do processo de certificação. De 2005 a 2010 foram vendidos cerca de 135 mil $\mathrm{kg}$ de raiz de priprioca, a um preço médio de $\mathrm{R} \$ 3,00 / \mathrm{kg}$, o que resultou em cerca de $R \$ 450$ mil em receitas. Para participar da cadeia de suprimento da Natura, foi demandado às comunidades que o cultivo fosse feito com adubação orgânica, o que foi feito com apoio de agrônomos para capacitação de produtores e adaptação de técnicas agrícolas aos locais de plantio. Com essa inovação no processo de cultivo, a coivara deixou de ser aplicada em todas as áreas de plantio, não só da priprioca. A produtividade desse novo sistema alcançou 42 toneladas/hectare, quase o triplo do obtido com a coivara (Mota, Conceição, \& Silva, 2008).

Essa integração evoluiu para o modelo de relacionamento de cadeia aberta com os seguintes passos: (1) a área de suprimento da Natura define o volume demandado de fragrância de priprioca e informa à Givaudan; (2) a área comercial da Givaudan consulta sua área técnica para definir o volume de óleo essencial de priprioca a ser demandado à Beraca; (3) a área comercial da Beraca repassa a informação à sua equipe de relacionamento com comunidades que, por sua vez, consulta a área de produção sobre o rendimento da transformação de priprioca em óleo essencial; (4) Natura e Beraca fazem em conjunto a solicitação da quantidade de priprioca a ser colhida; (5) Natura realiza a negociação de preço junto às três comunidades fornecedoras, levando em conta os custos de produção e a evolução do mercado; (6) Beraca faz a contratação da produção de priprioca nas três comunidades fornecedoras, adiciona sua margem e informa à Givaudan, para efetivação do contrato de compra do

Revista de Administração e Inovação, São Paulo, v. 10, n.1, p.232-256, Jan./Mar. 2013. 
volume demandado de óleo essencial; (7) Givaudan adiciona sua margem e informa à Natura, para efetivação do contrato de compra do volume demandado de fragrância de priprioca.

Os principais aspectos de indução identificados na cadeia de suprimento da priprioca estão resumidos na Figura 9. As duas estratégias apontadas por Seuring e Muller (2008b) foram observadas. Os componentes importantes da estratégia SMRP são os programas QLICAR e BIOQLICAR, enquanto os da estratégia SCMSP são a cooperação e o modelo de cadeia aberta. Observou-se nessa cadeia uma grande integração entre seus membros industriais, o que favoreceu o desenvolvimento de novos produtos de forma cooperativa.

\begin{tabular}{|c|c|}
\hline SMRP & SCMSP \\
\hline $\begin{array}{l}\text { - Givaudan e Beraca pertencem ao QLICAR e são } \\
\text { classificadas, respectivamente, como fornecedor "aliança" e } \\
\text { "estratégico". } \\
\text { - Ambas reportam trimestralmente informações sobre o } \\
\text { consumo de energia e água, geração de resíduos, emissões } \\
\text { de GEE, investimentos em educação formal e treinamentos } \\
\text { para funcionários e seus familiares, bem como para } \\
\text { comunidades no entorno; } \\
\text { - APROCAM reporta informações à Natura, com apoio e } \\
\text { monitoramento da Beraca no âmbito do programa } \\
\text { BIOQLICAR. }\end{array}$ & $\begin{array}{l}\text { - Cadeia foi estruturada a partir do } \\
\text { desenvolvimento de comunidades } \\
\text { fornecedoras, dentre elas a APROCAM; } \\
\text { - Cooperação entre Natura, Beraca e } \\
\text { APROCAM para que a comunidade } \\
\text { obtivesse a certificação orgânica; } \\
\text { - Modelo de cadeia aberta implantado, } \\
\text { conferindo transparência e garantindo } \\
\text { margens satisfatórias para todos os } \\
\text { membros. }\end{array}$ \\
\hline
\end{tabular}

Figura 9 - Indução e implementação de práticas socioambientais na cadeia da priprioca Fonte: Elaborado pelos autores

\subsection{ANÁLISE HORIZONTAL E VERTICAL DO CASO NATURA}

A análise horizontal dos casos estudados busca evidenciar o que ocorre de simétrico e assimétrico nas duas cadeias quanto à indução de práticas socioambientais pela empresa focal. A Figura 10 apresenta um resumo da estratégia SMRP, conforme o modelo de Seuring e Muller (2008b) esquematizado na Figura 4. A Natura não exige padrões socioambientais estabelecidos em normas de gestão como IS0 14001 e SA8000 como requisitos mínimos, mas estabelece seus próprios requisitos. Houve casos de fornecedores com certificação IS0 14001 que não atenderam os requisitos da Natura, o que significa que seus critérios são mais rigorosos comparativamente aos da norma.

Revista de Administração e Inovação, São Paulo, v. 10, n.1, p.232-256, Jan./Mar. 2013. 


\begin{tabular}{|c|c|c|c|}
\hline Prática & Natura & $\begin{array}{l}\text { Cadeia de suprimento } \\
\text { da priprioca }\end{array}$ & $\begin{array}{l}\text { Cadeia de suprimento } \\
\text { do cacau }\end{array}$ \\
\hline $\begin{array}{l}\text { Conjunto de } \\
\text { critérios de } \\
\text { avaliação } \\
\text { ampliado }\end{array}$ & $\begin{array}{l}\text { Estabelece requisitos } \\
\text { socioambientais no processo } \\
\text { de homologação de } \\
\text { fornecedores. } \\
\text { Pelo projeto QLICAR, os } \\
\text { fornecedores reportam } \\
\text { trimestralmente o } \\
\text { desempenho em consumo de } \\
\text { energia, água, geração de } \\
\text { resíduos, emissões de GEE, } \\
\text { investimentos em educação } \\
\text { formale treinamentos dos } \\
\text { funcionários e seus familiares } \\
\text { e suas comunidades. }\end{array}$ & $\begin{array}{l}\text { Givaudan e Beraca } \\
\text { pertencem ao QLICAR e } \\
\text { são cla ssificadas, } \\
\text { respectivamente, como } \\
\text { fornecedor "a liança"e } \\
\text { "estratégico". } \\
\text { Givaudan e Beraca } \\
\text { reportam trimestralmente } \\
\text { um conjunto de critérios } \\
\text { ampliado, ou seja, se auto- } \\
\text { a valiam em relação aos } \\
\text { indicadores apontados pela } \\
\text { Natura. }\end{array}$ & $\begin{array}{l}\text { Croda pertence ao QLICAR } \\
\text { e é classificada como } \\
\text { fornecedor estratégico. } \\
\text { Trimestralmente reporta um } \\
\text { conjunto de critérios } \\
\text { ampliado, para isso se auto- } \\
\text { a valia com indicadores } \\
\text { apontados pela Natura. } \\
\text { CABRUCA, com apoio da } \\
\text { equipe da Natura, reporta } \\
\text { dados socioambientais } \\
\text { quadrimestralmente por } \\
\text { meio do BIOQLICAR. }\end{array}$ \\
\hline $\begin{array}{l}\text { Auto- } \\
\text { avaliação de } \\
\text { fornecedores }\end{array}$ & $\begin{array}{l}\text { Fornecedores diretos devem } \\
\text { necessaria mente se } \\
\text { auto-a valiar em critérios } \\
\text { socioambientais e de } \\
\text { responsabilidade social. }\end{array}$ & $\begin{array}{l}\text { APROCAM, com apoio da } \\
\text { Beraca, reporta dados } \\
\text { socioambientais } \\
\text { quadrimestralmente por } \\
\text { meio do BIOQLICAR. }\end{array}$ & $\begin{array}{l}\text { IBC é o membro menos } \\
\text { integrado da cadeia. Não } \\
\text { participa do QLICAR. }\end{array}$ \\
\hline
\end{tabular}

Figura 10 - Indução e implementação de práticas socioambientais pela estratégia SMRP Fonte: Elaborado pelos autores

A Figura 11 apresenta um resumo da estratégia SCMSP conforme o esquema mostrado na Figura 5. Como se vê, a estratégia SCMSP é menos visível na cadeia do cacau do que na da priprioca. O fato do IBC não participar do BIOQLICAR evidencia uma comunicação menos intensa. A necessidade de uma estratégia SMRP também é menor na cadeia do cacau, pois a CABRUCA já era um produtor de cacau com certificação orgânica antes de se tornar fornecedor da Natura. Porém, um relacionamento com a Natura mais previsível e em escala significativa permitiu à CABRUCA estruturar melhor o seu negócio e deixar de vender matéria-prima no mercado spot nacional onde os preços são menores, focando-se apenas nas chocolateiras finas da Europa, Estados Unidos e Austrália que pagam melhores preços devido à certificação. 


\begin{tabular}{|c|c|c|c|}
\hline Prática & Natura & $\begin{array}{l}\text { Cadeia de suprimento da } \\
\text { priprioca }\end{array}$ & $\begin{array}{l}\text { Cadeia de suprimento do } \\
\text { cacau }\end{array}$ \\
\hline $\begin{array}{l}\text { Impactos e } \\
\text { requisitos com } \\
\text { base em } \\
\text { a va liação do ciclo } \\
\text { de vida (LCA) } \\
\end{array}$ & $\begin{array}{l}\text { A Natura impõe } \\
\text { requisitos com base } \\
\text { em LCA dos ativos da } \\
\text { biodiversidade e de } \\
\text { embalagens PET. }\end{array}$ & $\begin{array}{l}\text { O selo orgânico do IBD foi } \\
\text { um requisito da Natura à } \\
\text { APROCAM. }\end{array}$ & $\begin{array}{l}\text { O selo orgânico do IBD foi } \\
\text { um critério de seleção de } \\
\text { fornecedores que conduziu a } \\
\text { Natura à escolha da } \\
\text { CABRUCA. }\end{array}$ \\
\hline $\begin{array}{l}\text { Comunicação } \\
\text { incrementada }\end{array}$ & \multirow{2}{*}{$\begin{array}{l}\text { No relacionamento } \\
\text { com os parceiros via } \\
\text { QLICAR, bem como } \\
\text { nas cadeias de ativos } \\
\text { da biodiversidade, via } \\
\text { BIOQLICAR. }\end{array}$} & \multirow{2}{*}{$\begin{array}{l}\text { O modelo de cadeia aberta } \\
\text { demanda comunicação } \\
\text { intensa entre os membros da } \\
\text { cadeia. } \\
\text { A participação de } \\
\text { APROCAM e Beraca no } \\
\text { BIOQLICAR é uma outra } \\
\text { evidência da maior } \\
\text { intensidade de comunicação. }\end{array}$} & \multirow{2}{*}{$\begin{array}{l}\text { O modelo de cadeia aberta } \\
\text { demanda comunicação } \\
\text { intensa entre os membros da } \\
\text { cadeia. } \\
\text { Não participação do IBC no } \\
\text { BIOQLICAR. }\end{array}$} \\
\hline $\begin{array}{l}\text { Comunicação de } \\
\text { critérios aos } \\
\text { fornecedores }\end{array}$ & & & \\
\hline $\begin{array}{l}\text { Desenvolvimento } \\
\text { de fornecedores } \\
\text { em temas } \\
\text { socioambientais }\end{array}$ & $\begin{array}{l}\text { Em especial nas } \\
\text { cadeias de ativos da } \\
\text { biodiversidade } \\
\text { examinadas em } \\
\text { detalhe. }\end{array}$ & $\begin{array}{l}\text { A APROCAM foi } \\
\text { desenvolvida pela Natura em } \\
\text { conjunto com a Beraca. } \\
\text { O desenvolvimento envolveu } \\
\text { capacitação técnica, de gestão } \\
\text { organizacional, bem como de } \\
\text { adaptação a os requisitos da } \\
\text { certificação orgânica. }\end{array}$ & $\begin{array}{l}\text { Não houve a necessidade, } \\
\text { pois a CABRUCA já era um } \\
\text { produtor com certificação } \\
\text { orgânica. } \\
\text { Houve apoio da Natura em } \\
\text { capacitação técnica para } \\
\text { gestão da cooperativa. }\end{array}$ \\
\hline
\end{tabular}

Figura 11: Indução e implementação de práticas socioambientais pela estratégia SCMSP Fonte: Elaborado pelos autores

A análise vertical (Figura 12) procura evidenciar os instrumentos usados pela Natura afinados com as estratégias de indução do modelo de Seuring e Muller (2008b).

\begin{tabular}{|c|c|}
\hline Estratégia & Instrumento \\
\hline SMRP & $\begin{array}{l}\text { - } \quad \text { Auto-a valiação dos fornecedores (qualidade, meio ambiente e responsabilidade social). } \\
\text { - Cláusula de direitos humanos em contratos classificados como significativos: (a) valor: } \\
\text { superior a R\$ } 200 \text { mil; (b) não relacionado a um projeto estratégico; (c) fundamental } \\
\text { para o negócio da Natura; (d) parte contratada é de difícil substituição por outro } \\
\text { fornecedor; (e) traz riscos à imagem da companhia; (f) envolve propriedade intelectual; } \\
\text { aquisições de imóveis; doações e patrocínio. } \\
\text { - Certificação orgânica (ex. IBD), florestal (ex. FSC) e agrícola (ex. SAN) } \\
\text { - } \quad \text { Programas de treinamento de fornecedores para atendimento de requisitos mínimos. } \\
\text { - } \quad \text { Programas de treinamento de fornecedores para elaborar relatórios de sustentabilidade. }\end{array}$ \\
\hline SCMSP & $\begin{array}{l}\text { - Produtos desenvolvidos com tecnologias limpas visando redução dos impactos } \\
\text { ambientais ao longo da cadeia de suprimento (ex. produtos da linha Ekos). } \\
\text { - } \quad \text { Fórmula vegetalizadas que priorizam o uso de matérias-primas de origem renovável. } \\
\text { - Uso de ativos da biodiversidade amazônica com rastreabilidade ou certificação de } \\
\text { origem. } \\
\text { - Aplicação do conceito de preço justo para as comunidades fornecedoras. } \\
\text { - } \quad \text { Repartição de benefícios pelo uso do patrimônio genético. }\end{array}$ \\
\hline
\end{tabular}

Figura 12: Instrumentos das estratégias de indução utilizadas pela Natura Fonte: elaboração própria. 
A pesquisa verificou que os programas de relacionamento com fornecedores da Natura, como QLICAR, BIOQLICAR e PCA, são ações de imposição de requisitos próprias da estratégia SMRP, mas também são partes do desenvolvimento e melhoria do desempenho socioambiental da cadeia como um todo, sendo, portanto, instrumentos da estratégia SCMSP. Esses programas, que já existiam como ferramentas de gestão de fornecedores, passam a incorporar atributos de sustentabilidade que alcançaram a empresa por meio de pressões e incentivos de clientes, governos e outras partes interessadas, conforme apontado por Seuring e Müller (2008b) e descrito na seção 2. Também foi observado que o monitoramento e a colaboração/cooperação ocorrem nas duas estratégias, uma possibilidade não considerada explicitamente no modelo desses autores. Com base nos achados dessa pesquisa pode-se propor a adição do monitoramento e da colaboração/cooperação como instrumentos das estratégias SMRP e SCMSP.

\section{CONCLUSÃO}

Este trabalho insere-se no campo de pesquisa de SCM em convergência com as áreas de inovação e gestão socioambiental. A incorporação de preocupações socioambientais à SCM gerou o conceito de SSCM, sendo que entre os modelos propostos, o de Seuring e Müller (2008b) é um dos mais interessantes porque as estratégias contempladas, a SMRP e a SCMSP, são na realidade estratégias de inovação para transitar da SCM para a SSCM. Por isso, esse modelo tem merecido atenção e contribuições de pesquisadores com foco em inovação, operações e estratégia, dentre outros, e está se tornando uma referência para pesquisadores de sustentabilidade e de SCM. Esse modelo foi usado na presente pesquisa, na qual foi possível verificar sua consistência com a SCM no que tem de mais consolidado, como a gestão de fornecedores, gestão da demanda, desenvolvimento de produtos, logística, dentre outras áreas.

Para responder a questão de pesquisa foi realizada uma pesquisa com base em estudos de casos de duas cadeias de suprimentos da Natura tomadas à montante desta e alcançando as fontes de matérias-primas originadas da biodiversidade brasileira. Os critérios de escolha da empresa e das cadeias atenderam uma solicitação de autores ligados ao tema da SSCM, alguns citados, de que os estudos sobre este tema têm contemplado poucos elos da cadeia, em geral uma empresa e seus fornecedores de primeiro nível. Esta pesquisa procurou sanar essa deficiência, sendo essa uma de suas contribuições. Outra contribuição foi verificar a aplicação do modelo numa empresa considerada

Revista de Administração e Inovação, São Paulo, v. 10, n.1, p.232-256, Jan./Mar. 2013. 
exemplar em termos de sustentabilidade segundo entidades independentes reconhecidas pela sociedade brasileira. O uso do estudo de caso permitiu identificar instrumentos, conhecer em detalhe os processos de decisão, as motivações, as pressões e outras questões envolvidas na indução pela empresa focal de práticas de sustentabilidade na cadeia de suprimento. Os estudos de casos são apropriados para confirmar ou não teorias, bem como para aperfeiçoá-las, conforme ensina Eisenhardt (1989). Sobre este aspecto, o modelo que serviu de base para a pesquisa mostrou-se adequado ao estudo de gestão de cadeias complexas que tratam de relações complexas e ainda não suficientemente consolidadas. A pesquisa permitiu também sugerir acréscimos a esse modelo, como a inclusão do monitoramento socioambiental e da colaboração/cooperação em ambas as estratégias.

A pesquisa apresenta várias limitações, a primeira diz respeito ao estudo de caso, um método de pesquisa que não autoriza fazer generalizações sobre os seus resultados. O estudo centrado apenas em duas cadeias de suprimento de insumos da biodiversidade confere ainda mais especificidade aos resultados. Outra limitação vem do fato de não considerar as cadeias em sua totalidade, para verificar o ciclo de vida do produto completo conhecido pela expressão do berço ao túmulo, isto é, desde a origem das matérias-primas até o descarte final após o uso. Sobretudo quando se considera que a empresa estudada atua no segmento de cosméticos, cujo principal impacto ambiental do produto quando chega ao mercado se dá pelo descarte das embalagens. Essa limitação serve como uma sugestão para a realização de estudo para avaliar as práticas socioambientais por ela induzidas na cadeia reversa relacionada com o pós-consumo dos produtos resultantes dos seus negócios. Uma terceira limitação diz respeito às cadeias priorizadas neste estudo, ambas associadas ao uso de recursos naturais renováveis. A escolha de uma cadeia suprimento da empresa focal cujo produto seja, por exemplo, uma commodity química oriunda de recursos não renováveis, poderia trazer um contraste interessante à pesquisa.

A incorporação de preocupações afinadas com o desenvolvimento sustentável se dá por meio de inovações de todos os tipos e são as empresas focais das cadeias suas principais indutoras. A SSCM tem um longo caminho a percorrer, pois a inserção de questões ligadas aos pilares social e ambiental desse modelo requer novos conhecimentos, o que enseja muitos estudos e experimentações. Espera-se que a pesquisa relatada contribua no processo de construção teórica dessa nova área de estudo.

Revista de Administração e Inovação, São Paulo, v. 10, n.1, p.232-256, Jan./Mar. 2013. 


\section{REFERÊNCIAS}

Andersen, M., \& Skjoett-Larsen, T. (2009). Corporate social responsibility in global supply chains. Supply Chain Management: an International Journal, 14(2), 75-86.

Bakker, F., \& Nijhof, A. (2002). Responsible chain management: a capability assessment framework. Business Strategy and the Environment, 11(1), 63-75.

Beamon, B. M. (1999). Designing the green supply chain. Logistics Information Management, 12(4), $332-42$.

Bolsa de Valores de São Paulo (2011). Índice de sustentabilidade empresarial. Recuperado em 20 Junho, 2011, de http://www.bmfbovespa.com.br/indices/ResumoIndice.aspx? Indice=ISE.

Carter, C. R., \& Rogers, D. S. (2008). A framework of sustainable supply chain management: moving toward new theory. International Journal of Physical Distribution \& Logistics management, 38(5), 360-387.

Chesbrough, H. (2003). Open innovation: the imperative for creating and profiting from technology. Boston: Harvard Business School Press.

Comissão Mundial sobre Meio Ambiente e Desenvolvimento. (1991). Nosso futuro comum. Rio de Janeiro: FGV.

Creswell, J. W. (2010). Projeto de pesquisa: métodos qualitativo, quantitativo e misto (3a ed.). Porto Alegre: Artmed.

Eisenhardt, K. M. (1989). Building theories from case study research. Academy of Management Review, 14(4), 532-550.

Elkington, J. (2004). Enter the Triple Bottom Line. In A. HENRIQUES, \& J. RICHARDSON (Orgs.), The triple bottom line, does it all add up? assessing the sustainability of business and csr (pp. 116). London: Earthscan.

Jenkins, R. (2001). Corporate codes of conduct: self-regulation in a global economy. Recuperado em 04 de abril, 2012, de http://www.unrisd.org/unrisd/website/document.nsf/240da49ca467a53f80256b4f005ef245/e3b3e7 8bab9a886f80256b5e00344278/\$FILE/jenkins.pdf.

Kemp, R., \& Foxon, T. (2007). Eco-innovation from an innovation dynamics perspectives. Recuperado em 06 de junho, 2011, de http://www.merit.unu.edu/MEI/deliverables/MEI\%20D1\%20Ecoinnovation\%20from\%20an\%20innovation\%20dynamics\%20pespective.pdf.

Kemp, R., \& Pearson, P. (2007). Final report MEI project about measuring eco-innovation. Recuperado, em 06 de junho, 2011, de http://www.oecd.org/env/consumptioninnovation/43960830.pdf. 
Lippman, S. (2001). Supply chain environmental management. Environmental Quality Management, 11(2), 11-14.

Maia, J. G. S., \& Zoghbi, M. G. B. (1998). Óleos essenciais da Amazônia: inventário da flora aromática. In L. J. G. Faria, \& C. M. L. Costa (Orgs.), Tópicos especiais em tecnologia de produtos naturais (pp. 25-53). Belém: UFPA/NUMA/POEMA.

Mota, M. G. C., Conceição, C. C. C., \& Silva, A. B. (2008). Análise da cadeia produtiva e comercial da priprioca. In R. C. V. Potiguara, \& M. G. B Zoghbi (Orgs.), Priprioca: um recurso aromático do Pará (pp. 175-188). Belém: MPEG/UEPA.

Organisation for Economic Co-operation and Development. (2005). Oslo manual: guidelines for collecting and interpreting innovation data (3e ed.).Paris: Author.

Pagell, M., \& Wu, Z. (2009). Building a more complete theory of sustainable supply chain management using case studies of 10 exemplars. Journal of Supply Chain Management, 45(2), 3756.

Park-Poaps, H., \& Rees, K. (2010). Stakeholder forces of socially responsible supply chain management orientation. Journal of Business Ethics, 92(2), 305-322.

Seuring, S. (2005). Case study research in supply chains - an outline and three examples. In H. Kotzab, S. Seuring, M. Müller, \& G. Reiner (Orgs.), Research methodologies in supply chain management (pp. 235-249). Heidelberg: Physica-Verlag.

Seuring, S., \& Müller, M. (2008a). Core issues in sustainable supply chain management - a Delphi Study. Business Strategy and the Environment, 17, 455-66.

Seuring, S., \& Müller, M. (2008b). From a literature review to a conceptual framework for sustainable supply chain management. Journal of Clean Production, 16(15), 1699-1710.

Seuring, S., Sarkis, J., Müller, M., \& Rao, P. (2008). Sustainability and supply chain management. Journal of Cleaner Production, 16(15), 1545-1551.

Srivastava, S. (2007). Green supply-chain management: a state-of-the-art literature review. International Journal of Management Reviews, 9(1), 53-80.

Walker, H., Sisto, L., \& Mcbain, D. (2008). Drivers and barriers to environmental supply chain management practices: lessons from the public and private sectors. Journal of Purchasing and Supply Management, 14(1), 69-85.

Yin, R. K. (2010). Estudo de caso: planejamento e métodos (A. Thorell, Trad.) (4a ed.). Porto Alegre: Bookman.

Zoghbi, M. G. B., Guilhon, G. M. S., Andrade, E. H. A., \& Vilhena, K. S. S. (2008). Química das espécies de Cyperus conhecidas como priprioca. In R. C. V. Potiguara, \& M. G. B Zoghbi. (Orgs.), Priprioca: um recurso aromático do Pará (pp. 53-76). Belém: MPEG/UEPA. 


\title{
SOCIAL AND ENVIRONMENTAL INNOVATIONS IN SUPPLY CHAIN: A CASE STUDY ON THE ROLE OF FOCAL COMPANY
}

\begin{abstract}
This article presents the results of a research that aims to answer the following question: how does the focal company drive and implement innovative social and environmental practices throughout a supply chain oriented towards sustainability? A focal company is one that rules or coordinates the supply chain, provides the direct contact to the costumer and designs the product offered by the chain. Initially, a discussion on supply chain management and sustainability is presented to define the conceptual framework of the research reported and then, models of sustainable supply chain management are examined. These chains aim to achieve simultaneously economic, social and environmental positive impacts in accordance with the objectives of sustainable development, concept that in the business context has the triple bottom line (TBL) model as one of its most important expressions. A case study is, then, presented and it involves two supply chains based on biodiversity assets and encompasses six organizations upstream of the focal company. Two innovation induction strategies are considered, one centered on requirements imposed on suppliers and other oriented in developing new products. The study shows evidence that innovation in supply chains oriented towards sustainability require the creation of induction instruments by the focal company, as well as cooperation among participants, points out the relevance of the induction framework adopted and its possibilities for replication. The study also allows making additions to this model thereby contributing to theory building on sustainable supply chain management and its relation to sustainable innovations.
\end{abstract}

Keywords: Innovation; Sustainability; Sustainable supply chain; Focal company; Biodiversity.

Data do recebimento do artigo: 10/12/2012

Data do aceite de publicação: 15/02/2013

Revista de Administração e Inovação, São Paulo, v. 10, n.1, p.232-256, Jan./Mar. 2013. 